\title{
Morphological variation and integration of dentition in the Arctic fox (Vulpes lagopus): effects of island isolation
}

\author{
Olga G. Nanova
}

\begin{abstract}
We examined geographic variation in the shape of lower and upper rows of cheek teeth and variation in their morphological integration in Arctic foxes Vulpes lagopus (L., 1758). We found similarity in the structure of the variation in shape and morphological integration. Mednyi Island Arctic foxes $(V$. lagopus semenovi Ognev, 1931) were distinct from the other Arctic fox populations studied in terms of both the shape of cheek tooth rows and correlation of structure. Bering Island Arctic foxes ( $V$. lagopus beringensis Merriam, 1902), which are genetically similar to Mednyi Island foxes, were closer to mainland Arctic foxes with respect to the shape of cheek tooth rows and modular structure. Elongation of the edges of both lower and upper carnassials, molar enlargement, and coordinated rotation of premolars lingually were observed in Mednyi Island Arctic foxes when compared with mainland Arctic foxes. The modularity of lower and upper cheek tooth rows was studied. Two modules were found in both lower and upper tooth rows. Lower tooth rows comprised premolar and molar modules. In upper tooth rows, molars with the fourth premolar (the carnassial) and small premolars formed two distinct modules. Masking of developmental integration by functional integration was shown for upper tooth rows of Arctic foxes.
\end{abstract}

KEY WORDS: Arctic fox, geometric morphometrics, island isolation, modularity, morphological integration, Vulpes lagopus.

Olga Nanova [nanovaolgag@gmail.com], Zoological Museum, Moscow State University, Bolshaya Nikitskaya str. 6, Moscow 125009, Russia.

\section{Морфологическая изменчивость и корреляционная структура признаков зубов песца (Vulpes lagopus): эффект островной изоляции}

\section{О.Г. Нанова}

РЕЗЮМЕ. Исследована географическая изменчивость формы нижних и верхних зубных рядов и изменчивость корреляционной структуры зубов у песцов Vulpes lagopus (L., 1758). Показано, что изменчивость корреляционной структуры признаков отражает морфологическую изменчивость соответствующих структур. Так, песец о-ва Медный (V. lagopus semenovi Ognev, 1931) наиболее отличен как по форме зубных рядов, так и по корреляционной структуре от других проанализированных популяций. Песец о-ва Беринга (V. lagopus beringensis Merriam, 1902) по форме зубных рядов и по корреляционной структуре ближе к материковым популяциям, чем к генетически и экологически более близкому песцу о-ва Медный. У песцов о-ва Медный найдено согласованное увеличение режущих частей нижнего и верхнего хищнических зубов, удлинение моляров и согласованный разворот премоляров в лингвальную сторону. Исследована модульность нижнего и верхнего зубных рядов. И в нижнем, и в верхнем зубном ряду обнаружено по два модуля. В нижнем зубном ряду премоляры и моляры представляют собой отдельные модули. В верхнем зубном ряду четвертый премоляр (хищнический зуб) входит в модуль моляров, а малые премоляры объединены в отдельный модуль. В верхнем зубном ряду функциональные корреляции маскируют корреляции, возникающие в результате общей истории развития морфологических структур.

КЛЮЧЕВЫЕ СЛОВА: песец, геометрическая морфометрия, островная изоляция, модульность, морфологическая интеграция, Vulpes lagopus. 


\section{Introduction}

Parts of organisms may be correlated with one another to various degrees (i.e., possess concordant variation). Organisms are usually organized in a modular manner, with complexes of tightly integrated parts, or modules, that are relatively independent from each other (Olson \& Miller, 1958; Cheverud, 1996; Klingenberg, 2008; Klingenberg \& Marugan-Lobon, 2013). Modularity can be caused by function, ontogeny, or pleiotropic effects of genes, and manifests itself as evolutionary trends or constraints (Gould, 1989; Hunt, 2007). The relationship between variation in morphology and correlation structure is still not well understood. Teeth are a relatively independent module in the skull (Butler, 1995; Stock, 2001; Dayan et al., 2002; Meiri et al., 2005). Dentition as a whole constitutes a developmental module that is partially independent from its surrounding skeletal parts (Stock, 2001). Intraspecific variation in teeth is not correlated with variation in the bones of the skull of Arctic foxes (Nanova, 2009). Teeth are also ideal structures with which to study modularity, owing to their serially homologous nature (Bateson, 1894; Kurten, 1953; Butler, 1967). All teeth in the tooth row are constructed from a common plan, with greater quantitative than qualitative differences among elements. Moreover, teeth do not grow after eruption, and this feature facilitates detection of ontogenetic shape-ontogeny correlations. Although teeth may wear with age of an individual, this potential bias can be eliminated by examining only subadult teeth.

We studied the correlation of cheek teeth of Arctic foxes Vulpes lagopus (L., 1758) and its geographic variation by employing geometric morphometric methods. Geometric morphometrics is well adapted to correlation analyses (Klingenberg, 2008; 2013; Klingenberg \& Merugan-Lobon, 2013). They include both powerful statistical methods and methods of visualization of variation in shape. MorphoJ software includes all the tools needed for the analyses of morphological integration (Klingenberg, 2011). Furthermore, the coordinate method captures spatial relationships between landmarks without selection of a set of traits.

Variation in tooth shape and correlation structure between the mainland and two Commander Islands Arctic fox populations was studied. Isolated island populations usually undergo rapid phenotypic changes compared to mainland populations of the same species (Mayr, 1967; Gould \& Eldredge, 1977; Millien, 2006). These phenotypic changes can be caused by both genetic drift and specific environmental conditions. It is unknown if correlation in the variation of structures reflects phenotypic variation.

Arctic foxes on the two Commander Islands, Bering Isl. (V. lagopus beringensis Merriam, 1902) and Mednyi Isl. (V. lagopus semenovi Ognev, 1931), have been isolated for approximately 10,000 years from mainland Arctic foxes (Goltsman et al., 1996; Goltsman et al., 2005; Geffen et al., 2007; Dzhykiya, 2008) by the ice- free waters of the Bering Sea. The island environment is not typical Arctic fox habitat, exhibiting a mild climate and an absence of rodents (Goltsman et al., 2005). The two Commander Islands populations are genetically similar but show a genetically distant relationship with other Arctic fox populations (Geffen et al., 2007). Arctic foxes living on the mainland ( $V$. lagopus lagopus L., 1758), disperse widely and therefore constitute a single mainland subspecies (Dalén et al., 2005).

There are numerous morphological differences between island and mainland Arctic foxes. Island subspecies have larger body and cranial sizes than those on the mainland (Tsalkin, 1944; Goltsman et al., 2005; Zagrebelnyi \& Puzachenko, 2006; Nanova, 2009, 2010). The cranium differs among the subspecies not only in size but also in form, as it is wider at the carnassial teeth and zygomatic arches, with relatively stronger developed cranial sagittal crests, in both island subspecies (Nanova, 2009).

Our goal was to describe the correlations of cheek teeth in Arctic fox and determine if correlations reflect interpopulation phenotypic variation. To accomplish this, we addressed the following objectives: 1) examine and compare phenotypic variation among populations and the variation in covariance matrices; 2) test hypotheses about the modular structure of lower and upper cheek tooth rows at the interpopulation level; 3) estimate the correlation between lower and upper cheek tooth rows at the interpopulation level.

\section{Material and methods}

Eleven landmarks for the lower cheek tooth row and 16 landmarks for the upper cheek tooth row (Fig. 1, Tab. 1) were digitized on occlusal surfaces of $70 \mathrm{spec}-$ imens from Arctic fox from the following localities: Chukotka ( $n=19,10$ males and 9 females); Arkhangelsk region ( $n=19,10$ males and 9 females); Bering Island ( $n=19,10$ males and 9 females); Mednyi Island ( $n=13,8$ males and 5 females). Only subadult animals with non-erased teeth were included in the analysis. As it was shown in previous studies (Pavlinov \& Nanova, 2008; Nanova, 2009), there are no differences between males and females of Arctic fox in teeth shape. So, we analysed geographical variation with including both males and females in the samples.

All specimens were housed at the Zoological Museum of M.V. Lomonosov Moscow State University. Images of teeth were captured with Canon EOS 350D, lens Canon Macro $100 \mathrm{~mm}$. To capture teeth occlusal plane, camera was placed parallel to hard palate of each skull.

We excluded the lower first premolar (p1) and third molar (m3) because they were poorly preserved on dry skulls, and their rounded shape prevented the location of homological landmarks. TPSdig was used for digitizing (Rohlf, 1996, 2015). We conducted all morphometric analyses with MorphoJ software (Klingenberg, 2011); all analyses for lower and upper landmark sets were conducted separately. 

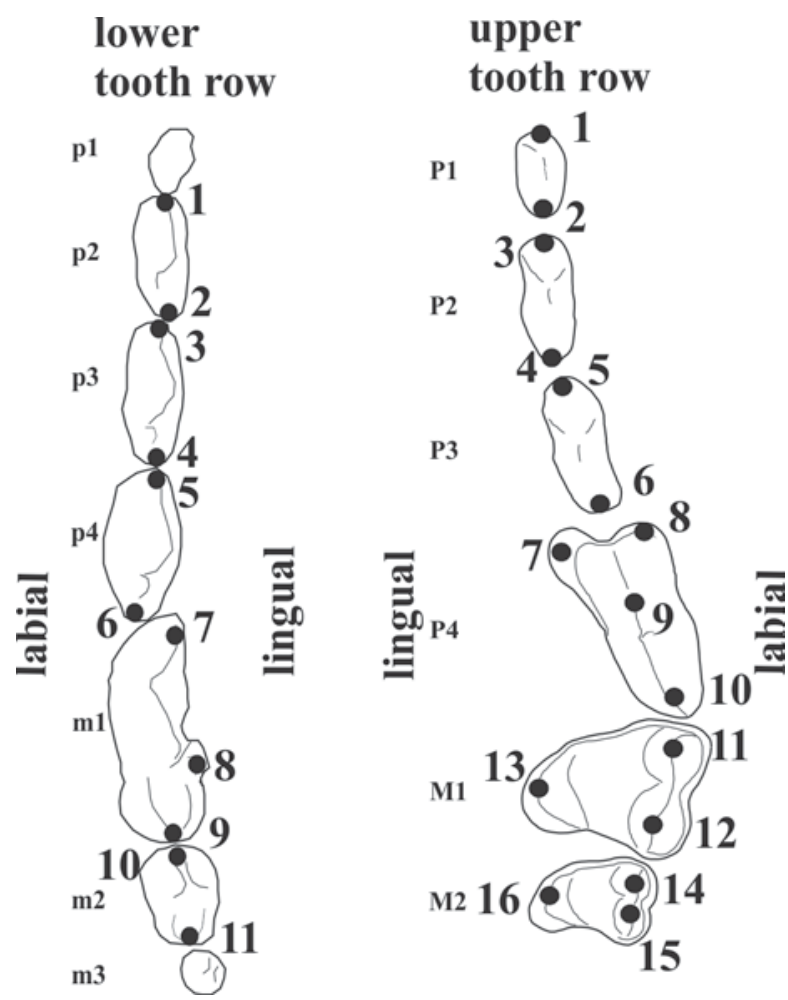

Fig. 1. Landmarks employed in the analyses: left, lower cheek tooth row; right, upper cheek tooth row.

We created a wireframe for the lower and upper landmark sets in order to better visualize variation in shape. Shape information was extracted from the landmark coordinates with a generalized full Procrustes fit (Dryden \& Mardia, 1998). Principal component analysis (PCA) was performed to estimate structure variation. We calculated average Procrustes distances between localities and estimated their significance via cross-validation with 10000 permutations. We calculated average shapes for each locality and added these to the PCA.

We calculated covariance matrices for each locality. We then performed a principal coordinate analysis (PCoA, as implemented in MorphoJ) on these matrices to assess differences in correlation structure among Arctic fox populations. PCoA is similar to PCA in that both are an ordination approaches, but PCoA is based on matrix distances between objects (covariance matrices in this instance). We calculated correlations between covariance matrices with including diagonal blocks. We tested for modularity employing all 70 specimens of lower and upper tooth rows. By definition, modules are assemblages of parts that are highly integrated internally and relatively independent of other such assemblages (Cheverud, 1996; Wagner, 1996; Klingenberg, 2008, Klingenberg, 2013; Klingenberg \& Merugan-Lobon, 2013). Thus, criterion of assessing modularity was based on the expectation that covariation among subsets of landmarks must be weaker than
Table 1. Description of the employed landmarks.

\begin{tabular}{|l|l|}
\hline \multicolumn{2}{|l|}{ Lower tooth row } \\
\hline 1 & $\begin{array}{l}\text { The most anterior edge of the second lower premolar } \\
\text { p2) }\end{array}$ \\
\hline 2 & The most posterior edge of p2 \\
\hline 3 & $\begin{array}{l}\text { The most anterior edge of the third lower premolar } \\
\text { p3) }\end{array}$ \\
\hline 4 & The most posterior edge of p3 \\
\hline 5 & $\begin{array}{l}\text { The most anterior edge of the fourth lower premolar } \\
\text { (p4) }\end{array}$ \\
\hline 6 & The most posterior edge of p4 \\
\hline 7 & Paraconid of lower the first molar (m1) \\
\hline 8 & Metaconid of m1 \\
\hline 9 & Hypoconulid of m1 \\
\hline 10 & The most anterior edge of the second lower molar (m2) \\
\hline 11 & The most posterior edge of m2 \\
\hline Upper tooth row \\
\hline 1 & The most anterior edge of the first upper premolar (P1) \\
\hline 2 & The most posterior edge of P1 \\
\hline 3 & $\begin{array}{l}\text { The most anterior edge of the second upper premolar } \\
\text { (P2) }\end{array}$ \\
\hline 4 & The most posterior edge of P2 \\
\hline 5 & $\begin{array}{l}\text { The most anterior edge of the third upper premolar } \\
\text { (P3) }\end{array}$ \\
\hline 6 & The most posterior edge of P3 \\
\hline 7 & Protocone of the fourth upper premolar (P4) \\
\hline 8 & Parastyle of P4 \\
\hline 9 & Paracone of P4 \\
\hline 10 & The most posterior edge of metastyle of P4 \\
\hline 11 & Paracone of the first upper molar (M1) \\
\hline 12 & Metacone of M1 \\
\hline 13 & Hypocone of M1 \\
\hline 14 & Paracone of the second upper molar (M1) \\
\hline 15 & Metacone of M2 \\
\hline
\end{tabular}

the covariation among other partitions of landmarks into subsets that are inconsistent with the modules. We used the RV coefficient to quantify the covariation among subsets of landmarks (Escoufier, 1973; Klingenberg, 2009). The RV coefficient is analogous to a squared correlation coefficient. The RV coefficient can be written as $R V=\operatorname{trace}\left(\mathrm{S}_{12} \mathrm{~S}_{21}\right) / \sqrt{\operatorname{trace}}\left(\mathrm{S}_{1} \mathrm{~S}_{1}\right) \operatorname{trace}\left(\mathrm{S}_{2} \mathrm{~S}_{2}\right)$. In this formula, $\mathrm{S}_{1}$ and $\mathrm{S}_{2}$ are the covariance matrices within the first and second subsets of landmarks. The off-diagonal blocks $\mathrm{S}_{12}$ and $\mathrm{S}_{21}$ are the matrices of covariances between the two subsets.

We used a permutation test with subsets of alternative partitions of the same number of landmarks. We computed all possible partitions.

There are two modules, premolars and molars, in cheek tooth rows based on ontogenetic and functional 

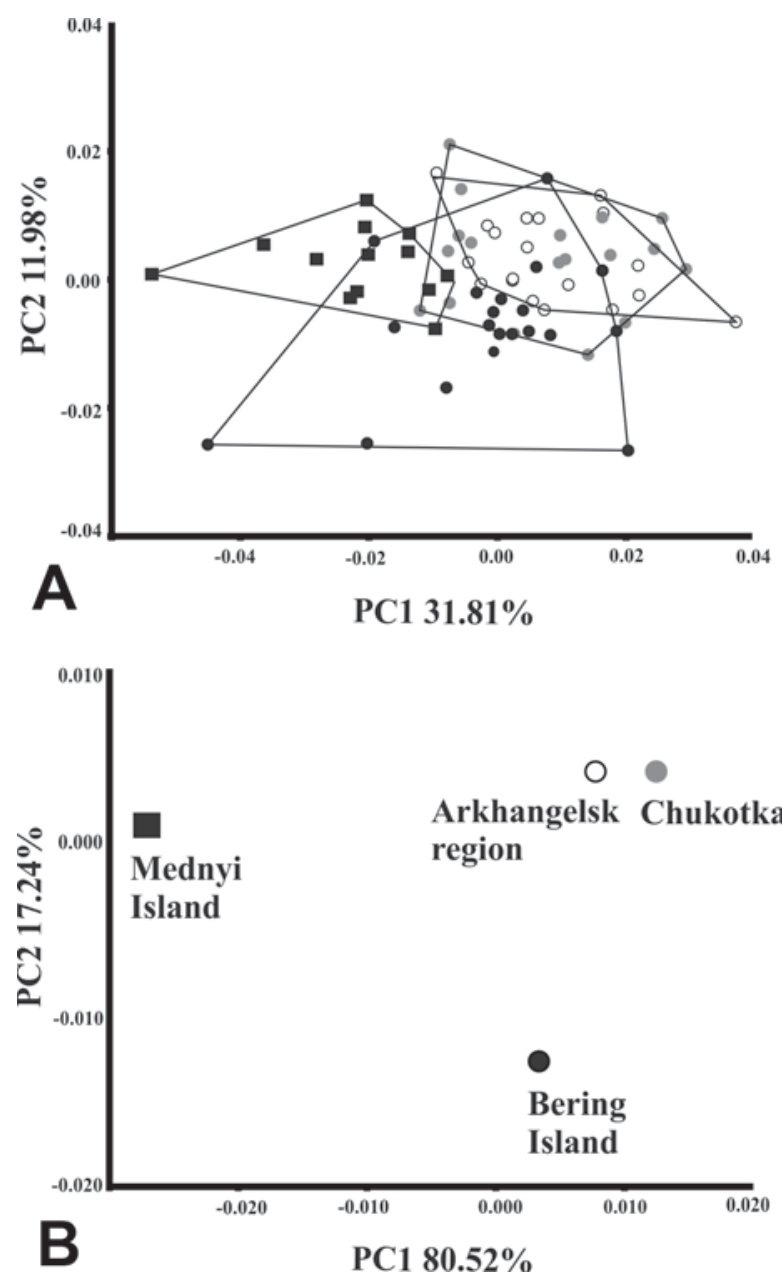

Fig. 2. Principal components analysis of the shape of the lower cheek tooth row, PC1 vs. PC2: A - all specimens are employed, B - averages by locality are employed; black squares - Mednyi Island, black circles - Bering Island, grey circles - Chukotka, transparent circles - Arkhangelsk region.

data. Therefore, for the lower cheek tooth row, we tested Hypothesis 1, which states there are two modules, premolars and molars. The first block (premolars) includes landmarks 1-6 and the second (molars) includes landmarks 7-11. In the upper cheek tooth row, the modular position of the fourth premolar (P4; carnassial) is ambiguous because it shares functionally with molars and possesses a complicated shape in comparison to the smaller premolars (P1-P3). Hence, we tested two hypotheses for the upper cheek tooth row. We tested Hypothesis 2, according to which the upper cheek tooth row consists of two ontogenetic modules, premolars, including carnassials, and molars. In this case, the first block includes landmarks 1-10 and the second block includes landmarks 11-16. Finally, we tested Hypothesis 3, according to which the cheek tooth row consists of two functional modules, small premolars and molars with the carnassial (P4), where the first block includes landmarks 1-6 and the second block includes landmarks 7-16. We determined pattern of covariation between lower and upper tooth rows with the partial least squares (PLS) method (Rohlf \& Corti, 2000; Klingenberg, 2009). In this analysis, we considered lower and upper tooth rows as two separate blocks. We performed a permutation test $(10,000$ permutations) against the null hypothesis of blocks independence.

\section{Results}

\section{Morphological variation \\ Mandible}

The first three principal components (PC 1-3) accounted for $55.20 \%$ of variation when all specimens were included in the analysis. PC1 accounted for $31.81 \%$ of variation and PC2 accounted for $11.98 \%$. Samples from the Chukotka and Arkhangelsk region overlapped in the space of PC1-PC2 (Fig. 2A). Samples from Mednyi Island were separated from all other samples by PC1. Sample from Bering Island was partly overlapped with both mainland and Mednyi Island samples. The variation of the shape along PC1 and PC2 is visualized in Figure 3. In the left part of PC1 where Mednyi Island specimens are located, p2 and p4 are rotated relative to other lower cheek teeth, the edge of $\mathrm{ml}$ is elongated, and $\mathrm{m} 2$ is enlarged.

When averages of samples were analysed (Fig. 2B), $\mathrm{PC} 1$ accounted for $80.52 \%$ of the variation, and PC2 for $17.24 \%$. Averages of two mainland samples were nearest to each other on the plot of PC1-PC2. The Mednyi Island average was the most distant from all three averages. The average of the Bering Island sample was closer to that of the mainland samples than the Mednyi Island average. Analysis of average Procrustes distances (Tab. 2) confirmed this result.

\section{Maxilla}

The pattern of maxilla variation was similar to that of the mandible (Fig. 4A).

The first three principal components accounted for $49.94 \%$ of variation when all specimens were included in the analysis. PC1 accounted for $23.00 \%$ of the variation, and PC2 accounted for $14.75 \%$. When averages of samples were analysed (Fig. 4B), PC1 accounted for $85.52 \%$ of the variation, whereas PC2 accounted for $9.05 \%$. Mednyi Island samples were separated from the three other samples by PC1. Mednyi Island specimens were distinct from other specimens by rotated P1-P3 relative to molars, a forward shift of $\mathrm{P} 4$, an elongated edge in P4, and enlarged M1-M2 (Fig. 5). Similar to lower cheek tooth rows, upper cheek tooth rows in Bering Island foxes had an intermediate position between Mednyi Island and the mainland specimens. Analysis of average Procrustes distances confirmed this result (Tab. 3). 

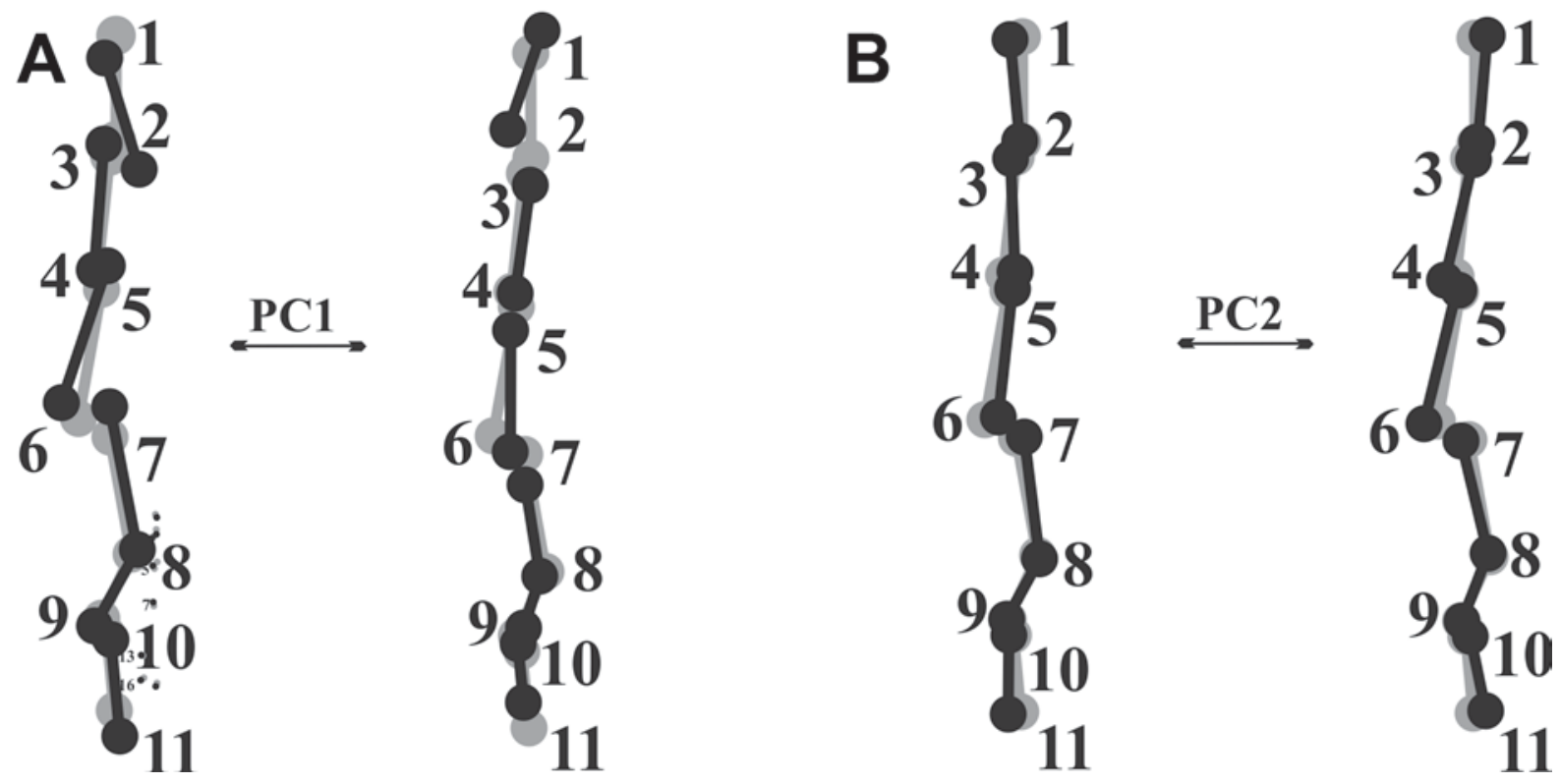

Fig. 3. Transformations of lower tooth row along two first PCs: A - PC1, B - PC2.

Table 2. Average Procrustes distances among shapes of lower tooth rows (below the diagonal) and $p$-value for permutation tests with 1000 permutation runs (above the diagonal).

\begin{tabular}{|c|c|c|c|c|}
\hline & Arkhangelsk region & Chukotka & Bering Isl. & Mednyi Isl. \\
\hline Arkhangelsk region & & 0.3210 & $<0.0001$ & $<0.0001$ \\
\hline Chukotka & 0.0078 & & $<0.0001$ & $<0.0001$ \\
\hline Bering Isl. & 0.0186 & 0.0196 & & $<0.0001$ \\
\hline Mednyi Isl. & 0.0365 & 0.0391 & 0.0337 & \\
\hline
\end{tabular}

Covariance matrix variation

In the lower cheek tooth row analysis, PCo1 accounted for $52.42 \%$ of total variation of covariance matrices, and $\mathrm{PCo} 2$ accounted for $36.20 \%$. In the upper cheek tooth row analysis, PCol accounted for $63.19 \%$ of the variation, whereas PCo2 accounted for $21.92 \%$.

For both lower and upper cheek tooth rows, covariance matrices of Mednyi Island foxes were the most distant from those of other studied samples by PCo1 (Fig. 6). In both analyses, the covariance matrix of the Bering Island sample was located between matrices of the mainland and Mednyi Island samples. Covariance matrices of mainland and Bering Island samples differed along $\mathrm{PCo} 2$.

Analyses of correlations between covariance matrices confirmed the principal coordinate analysis (Tab. 4). Covariance matrices of lower and upper cheek tooth rows of Mednyi Island foxes were poorly correlated with both the mainland and the Bering Island's covariance matrices. Covariance matrices of Bering Island sample were correlated with the mainland's covariance matrices at the same level as the covariance matrices of the Chukotka and Arkhangelsk regions were correlated.
Evaluating the hypotheses of modularity

Hypothesis 1. In this hypothesis, two blocks are recognized in the lower cheek tooth row: block 1 comprised landmarks 1-6, and block 2 was composed of landmarks 7-11. RV coefficient between lower premolars and molars was 0.36 . Number of all possible partitions was 116. Zero partitions (Fig. $7 \mathrm{~A}, 0.0 \%$ of all partitions) had a lower RV coefficient than the RV coefficient for the tested hypothesis. Therefore, Hypothesis 1 , according to which the lower cheek tooth row comprises two ontogenetic and functional modules, premolars and molars, was supported.

Hypothesis 2. Two blocks are recognized in the upper cheek tooth row: block 1 comprised landmarks 110 (includes carnassials), block 2 was composed of landmarks 11-15. The RV coefficient between upper premolars and molars was 0.50 . The number of all possible partitions was 964. Of all partitions, 215 (Fig. $7 \mathrm{~B}, 22.30 \%$ ) had a lower RV coefficient than that for the tested hypothesis. Hence, Hypothesis 2, according to which the upper cheek tooth row comprises two ontogenetic modules, premolars and molars, was rejected. 

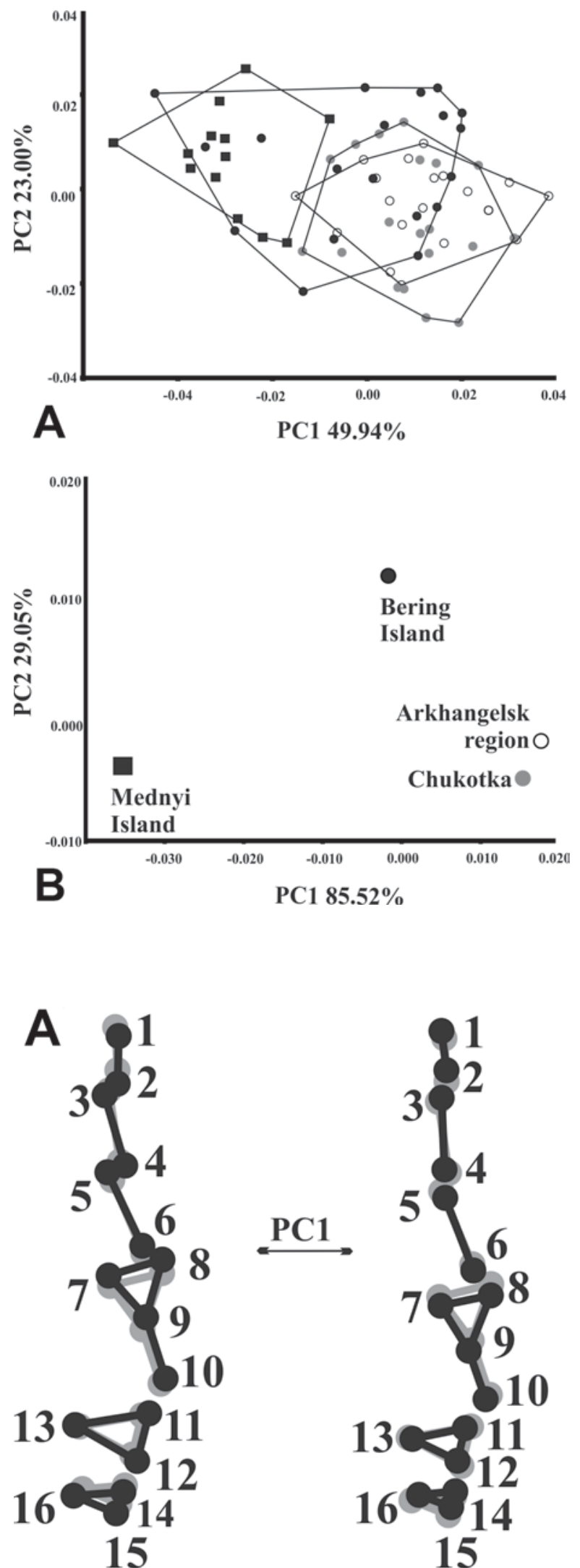

Fig. 4. Principal components analysis of the shape of the upper cheek tooth row, PC1 vs. PC2: A - all specimens are employed, B - averages by locality are employed; black squares - Mednyi Island, black circles - Bering Island, grey circles - Chukotka, transparent circles - Arkhangelsk region.

Hypothesis 3. Two blocks are recognized in the upper cheek tooth row: block 1 comprised landmarks $1-6$, and block 2 was composed of landmarks 7-15 (including carnassial). The RV coefficient between upper small premolars and molars with carnassials was 0.30 . The number of all possible partitions was 964 . One partition (Fig. 7C, 0.10\%) had a lower RV coefficient than that for the tested hypothesis. Therefore, Hypothesis 3, which states that the upper cheek tooth row comprises two functional modules, small premolars and molars with carnassials, was supported.

Lower and upper cheek tooth rows correlation

Significant correlation between shape of lower and upper tooth rows was found (Fig. 8) at the interpopulation level: RV coefficient was $0.38, p<0.0001(10,000$ permutations). The first PLSs accounted for $74.46 \%$ of joint total variation. As shown in Figure 8, the Mednyi Island sample occupies a detached space in the plot of PLS1 axes. Concurrent rotation to the lingual side of the lower and upper premolars, elongation of $\mathrm{m} 1$ trigon and the edge of $\mathrm{P} 4, \mathrm{~m} 2$ elongation with enlargement of M1 and M2, and a forward shift of P4 are exhibited.

Fig. 5. Transformations of upper tooth row along two first PCs: A - PC1, B - PC2. 
Table 3. Average Procrustes distances among shapes of upper tooth rows (below the diagonal) and $p$-value for permutation tests with 1000 permutation runs (above the diagonal).

\begin{tabular}{|c|c|c|c|c|}
\hline & Arkhangelsk region & Chukotka & Bering Isl. & Mednyi Isl. \\
\hline Arkhangelsk region & & 0.7500 & $<0.0001$ & $<0.0001$ \\
\hline Chukotka & 0.0078 & & $<0.0001$ & $<0.0001$ \\
\hline Bering Isl. & 0.0242 & 0.0241 & & $<0.0001$ \\
\hline Mednyi Isl. & 0.0504 & 0.0487 & 0.0340 & \\
\hline
\end{tabular}
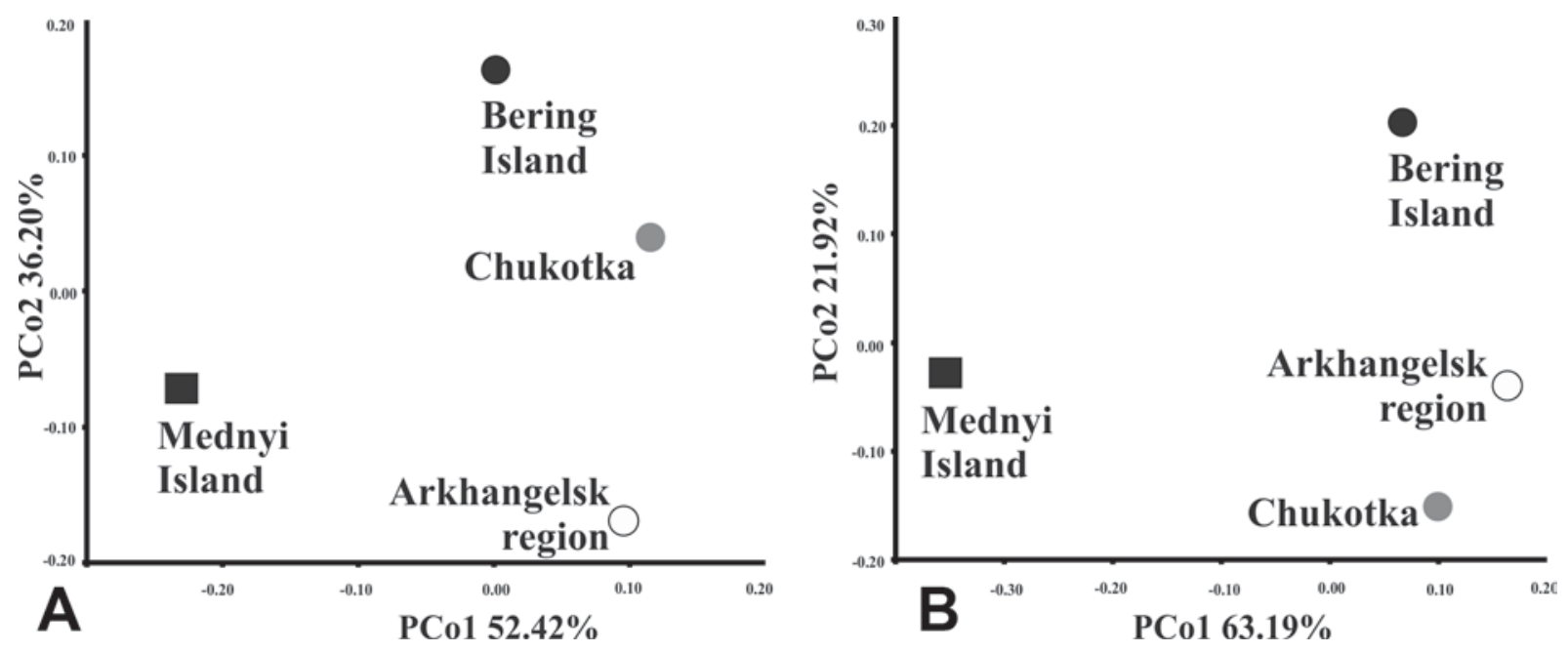

Fig. 6. Principal coordinate analysis of covariance matrices of geographical samples: A — lower cheek tooth row, B - upper cheek tooth row.

Table 4. Correlation coefficient among covariance matrices of localities for lower cheek tooth row (below the diagonal) and upper cheek tooth row (above the diagonal).

\begin{tabular}{|c|c|c|c|c|}
\hline & Arkhangelsk region & Chukotka & Bering Isl. & Mednyi Isl. \\
\hline Arkhangelsk region & & 0.6879 & 0.6610 & 0.4325 \\
\hline Chukotka & 0.7348 & & 0.6384 & 0.4757 \\
\hline Bering Isl. & 0.6488 & 0.7569 & & 0.4850 \\
\hline Mednyi Isl. & 0.6176 & 0.6093 & 0.6531 & \\
\hline
\end{tabular}

\section{Discussion}

Significant differences were found between Mednyi Island Arctic foxes and mainland Arctic foxes with respect to the shape of lower and upper tooth rows. Bering Island Arctic foxes were closer to mainland foxes in the shape of lower and upper tooth rows. This result is surprising, because Mednyi and Bering Island foxes are genetically similar (Geffen et al., 2007). Moreover, both Commander Islands populations have been isolated in similar environments (Zagrebelnyi, 2000b; Goltsman et al., 2005). In particular, they feed primarily on seabirds and marine mammals. Further, both Mednyi and Bering Island Arctic foxes are significantly heavier and have larger craniums than their mainland conspecifics, with average winter body masses of 5.0$7.0 \mathrm{~kg}$ for males and $4.5-6.0 \mathrm{~kg}$ for females, whereas these values on the mainland are $3.2-4.5 \mathrm{~kg}$ for males and 3.0-3.5 kg for females (Goltsman et al., 2005). Average condylobasal length of skull for males and females on Mednyi Island Arctic foxes is $130.0 \mathrm{~mm}$ and $123.3 \mathrm{~mm}$, respectively. These values on Bering Island are $132.2 \mathrm{~mm}$ and 124.9 respectively, and those for mainland foxes are $125.0 \mathrm{~mm}$ and $117.8 \mathrm{~mm}$ (Nanova, 2009). Differences in tooth row shape between Mednyi and Bering Island could be attributed to genetic drift and the differences in island area, and the consequent difference in island population size. Bering Island is 

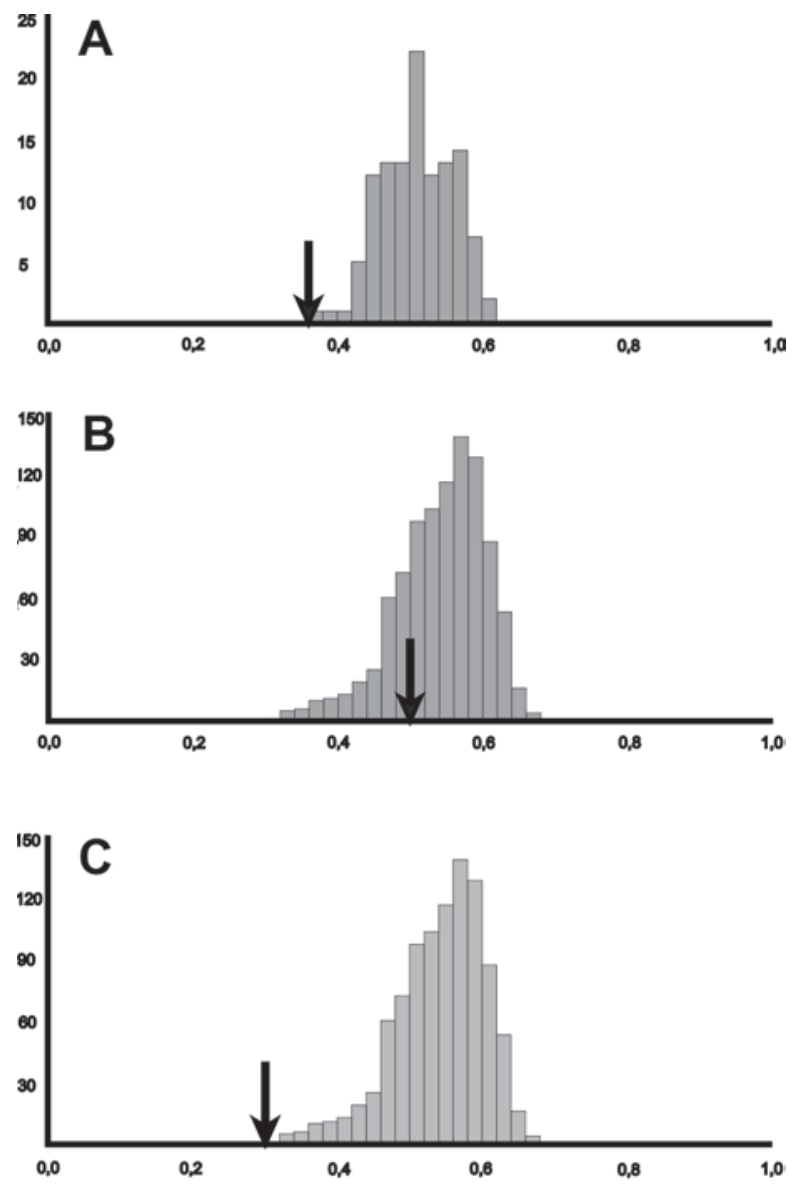

Fig. 7. Evaluating the hypotheses concerning the modularity for the lower and upper cheek tooth rows by comparing the covariation between premolars and molars with alternative partitions of the landmarks: A - Hypothesis 1, lower cheek tooth row, premolars vs. molars; B - Hypothesis 2, upper cheek tooth row, premolars vs. molars; C - Hypothesis 3, upper cheek tooth row, small premolars vs. molars with carnassials. The arrows indicate the RV coefficient between hypothesized modules, and the histograms represent the distribution of RV coefficients for the alternative partitions.

$1700 \mathrm{~km}^{2}$ and Mednyi Island is $186 \mathrm{~km}^{2}$. Currently, the number of Arctic foxes on Bering Island is approximately 1000 and that on Mednyi Island is approximately 120 . Thus, selection pressure is likely different on these two islands. Moreover, the observed differences between Bering and Mednyi Island Arctic foxes could be caused by ecological factors that affect fox morphology on a historical time scale. Further study of ecology and functional morphology of Commander Islands Arctic foxes is needed to reveal the reasons of differences between these two island fox populations.

Intraspecific variation in the shape and morphological integration of cheek teeth was found. The pronounced differences in tooth row shape between Mednyi Island Arctic foxes and those from both Bering Island and mainland were significantly connected with

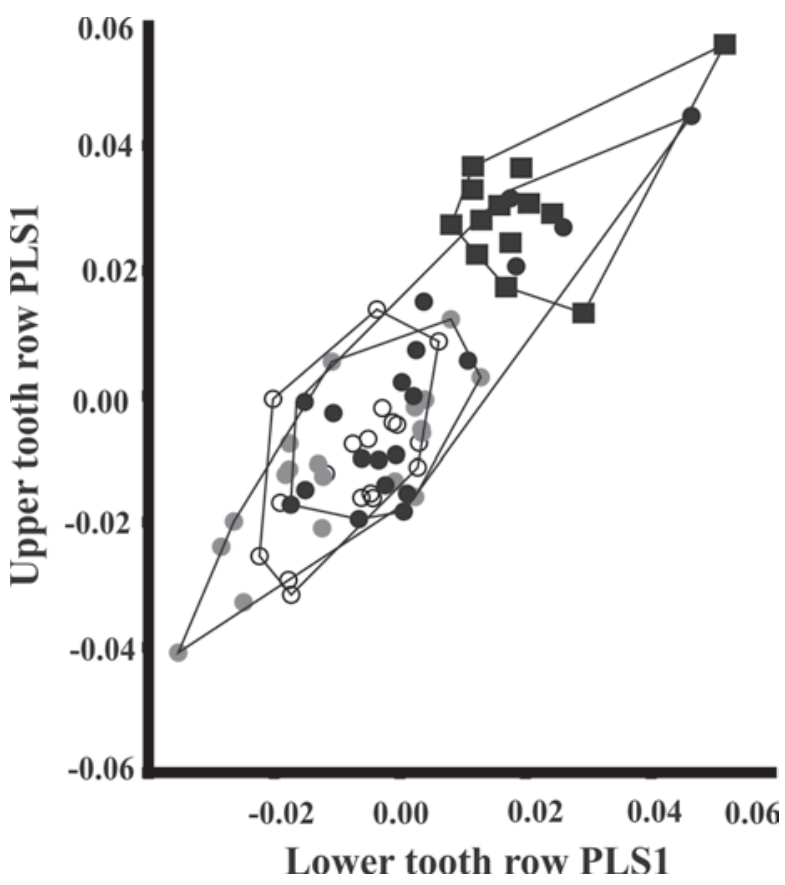

Fig. 8. PLS analysis of covariation between the lower and upper cheek tooth rows. PLS1 of the lower tooth row vs. PLS1 of the upper tooth row: black squares - Mednyi Island, black circles - Bering Island, grey circles - Chukot$\mathrm{ka}$, transparent circles - Arkhangelsk region.

a particular shape covariance structure. Ontogenetic and functional differences of cheek teeth in Mednyi Island foxes are expected based on this finding. The result is concordant with previous findings that allometric pattern of skull growth in Mednyi Island Arctic foxes is different from that in Bering Island and mainland Arctic foxes (Nanova, 2010).

Teeth play an important role in food acquisition and processing. Food sources of Arctic foxes on Mednyi Island and the mainland are different (Barabash-Nikiforov, 1937, 1939; Ilyina, 1950; Chelnokov, 1970; Smirin et al., 1979; Zagrebelnyi, 2000a, b; Goltsman et al., 2010). Rodents, the main prey of Arctic foxes on mainland (Angerbjörn et al., 1999; Anthony et al., 2000; Eide et al., 2004), are not found on Mednyi Island. The main prey of Arctic foxes on Mednyi Island is sea birds, generally Northern fulmar (Fulmarus glacialis; Goltsman et al., 2010). In winter, Mednyi Island foxes primarily feed on the carcasses of sea otters (Enhydra lutris; Zagrebelnyi, 2000a; Goltsman et al., 2010). The prey size of Mednyi Island Arctic foxes is larger in comparison to rodents. For instance, the average body weight of a Northern fulmar is $0.5-1.0 \mathrm{~kg}$, body length is $45 \mathrm{~cm}$, and wingspan is $100-110 \mathrm{~cm}$. This could be the reason for the significant shape differences in teeth of Mednyi Island foxes in comparison with mainland foxes. Elongation of edges of lower and upper carnassials and molars enlargement could be useful for the processing of large prey. Rotation of 
premolars lingually could be caused by the necessity to catch large, struggling birds. Size enlargements of Mednyi Island foxes indirectly confirm this assumption. Functional analysis for testing this hypothesis is warranted.

Modularity of the lower cheek tooth row reflects module ontogeny. In this case, premolars and molars are different modules. Modular structure in upper cheek tooth row is more complex. Here, modules are caused by functional reasons. For instance, the upper carnassials belong to the premolar group developmentally, but are strongly correlated with molars because they have a similar function as molars. In this study, we demonstrated that ontogenetic correlations could be masked by functional correlations in cheek tooth rows.

\section{Conclusions}

1. The variance in covariance matrices reflected geographical variation in the shape of tooth rows of Arctic foxes.

2. Mednyi Island Arctic foxes are distinct from both mainland and Bering Island Arctic foxes based on the shape of cheek tooth rows and covariation patterns.

3. Lower cheek tooth rows comprise two modules, premolars and molars. Upper cheek tooth rows include two modules as well. In this case, upper fourth premolars, the carnassials, belong to the molar module, and not to the premolar one. Therefore, in the upper cheek tooth row, functional correlations mask ontogenetic integration.

ACKNOWLEDGEMENTS. Funding for this study was provided through grant of Russian Science Foundation No. 14-50-00029.

\section{References}

Angerbjörn A., Tannerfeldt M. \& Erlinge S. 1999. Predatorprey relationships: Arctic foxes and lemmings // Journal of Animal Ecology. Vol.68. P.34-49.

Anthony R.M., Barten N.L. \& Seiser P.E. 2000. Foods of Arctic foxes (Alopex lagopus) during winter and spring in western Alaska // Journal of Mammalogy. Vol.81. P.820-828.

Barabash-Nikiforov I.I. 1937. [On the biology of Commander Islands Arctic foxes] // Proceedings of Arctic Institute. Vol.65. P.145-167 [in Russian].

Barabash-Nikiforov I.I. 1939. [On the diet of Mednyi Island Arctic foxes Alopex beringensis semenovi Ogn.] // Bulletin of Moscow Society of Naturalists. Vol.48. P.74-80 [in Russian].

Bateson W. 1894. Material for the Study of Variation, Treated with Special Regard to Discontinuity in the Origin of Species. London: Macmillan and Co. 628 p.

Butler P.M. 1967. Dental merism and tooth development // Journal of Dental Research. Vol.46. P.843-850.

Butler P.M. 1995. Ontogenetic aspects of dental evolution // International Journal of Developmental Biology. Vol.39. P.25-34.
Chelnokov F.G. 1970. [On the relationship between foxes and fur-seal cubs] // Problems of Kamchatka Geography. No.6. P.151-158 [in Russian].

Cheverud J.M. 1996. Developmental integration and the evolution of pleiotropy // American Zoologist. Vol.36. P.44-50.

Dalén L., Fuglei E., Hersteinsson P., Kapel C.M.O., Roth J.D., Samelius G., Tannerfeldt M. \& Angerbjörn A. 2005. Population history and genetic structure of a circumpolar species: the Arctic fox // Biological Journal of the Linnean Society. Vol.84. P.79-89.

Dayan T., Wool D. \& Simberloff D. 2002. Variation and covariation of skulls and teeth: modern carnivores and the interpretation of fossil mammals // Paleobiology. Vol.28. P.508-526.

Dryden I.L. \& Mardia K.V. 1998. Statistical Shape Analysis. Chichester: Wiley. 376 p.

Dzhykiya E.L. 2008. [Genetic Polymorphism of Commander Islands' Arctic Foxes (Alopex lagopus semenovi, Ognev 1931, Alopex lagopus beringensis, Merriam 1902)]. Avtoreferat Dissertatsii Kandidata Biologicheskikh Nauk [Abstract of PhD Dissertation in Zoology]. Moscow: M.V. Lomonosov Moscow State University. 20 p. [in Russian].

Eide N.E., Jepsen J.U. \& Prestrud P. 2004. Spatial organization of reproductive Arctic foxes Alopex lagopus: responses to changes in spatial and temporal availability of prey // Journal of Animal Ecology. Vol.3. P.1056-1068.

Escoufier Y. 1973. Le traitement des variables vectorielles / / Biometrics. Vol.29. P.751-760.

Geffen E., Waidyaratne S., Dalén L., Angerbjörn A., Vila C., Hersteinsson P., Fuglei E., White P.A., Goltsman M., Kapel C.M.O. \& Wayne R.K. 2007. Sea ice occurrence predicts genetic isolation in the Arctic fox // Molecular Ecology. Vol.16. P.4241-4255.

Goltsman M., Kruchenkova E.P. \& Macdonald D.W. 1996. The Mednyi Arctic foxes: Treating a population imperilled by disease // Oryx. Vol.30. P.251-258.

Goltsman M., Kruchenkova E.P., Sergeev S., Volodin I. \& Macdonald D.W. 2005. "Island syndrome" in a population of Arctic foxes (Alopex lagopus) from Mednyi Island // Journal of Zoology. Vol.267. P.405-418.

Goltsman M.E., Nanova O.G., Sergeev S.N. \& Shienok A.N. 2010. Food habits of the Arctic fox (Alopex lagopus semenovi) on Mednyi Island (North Pacific, Commander Islands) // Zoologicheskii Zhurnal. Vol.89. P.1246-1263 [in Russian with English summary].

Gould S.J. \& Eldredge N. 1977. Punctuated equilibria: the tempo and mode of evolution reconsidered // Paleobiology. Vol.3. P.115-151.

Gould S.J. 1989. A developmental constraint in Cerion, with comments on the definition and interpretation of constraint in evolution // Evolution. Vol.43. P.516-539.

Hunt G. 2007. Evolutionary divergence in directions of high phenotypic variance in the ostracode genus Poseidonamicus // Evolution. Vol.61. P.1560-1576.

Ilyina E.D. 1950. [Fur Farming on Islands]. Moscow: Mezhdunarodnaya Kniga. 198 p. [in Russian].

Klingenberg C.P. 2008. Morphological integration and developmental modularity // Annual Review of Ecology, Evolution, and Systematics. Vol.39. P.115-132. 
Klingenberg C.P. 2009. Morphometric integration and modularity in configurations of landmarks: tools for evaluating a-priori hypotheses // Evolution and Development. Vol.11. P.405-421.

Klingenberg C.P. 2011. MorphoJ: an integrated software package for geometric morphometrics // Molecular Ecology Resources. Vol.11. P.353-357.

Klingenberg C.P. 2013. Cranial integration and modularity: insights into evolution and development from morphometric data // Hystrix. Vol.24. P.43-58.

Klingenberg C.P. \& Marugan-Lobon J. 2013. Evolutionary covariation in geometric morphometric data: analyzing integration, modularity, and allometry in a phylogenetic context // Systematic Biology. Vol.62. P.591-610.

Kurten B. 1953. On the variation and population dynamics of fossil and recent mammal populations // Acta Zoologica Fennica. Vol.76. P.1-122.

Mayr E. 1967. The challenge of island faunas // Australian Natural History. Vol.15. P.369-374.

Meiri S., Dayan T. \& Simberloff D. 2005. Variability and correlations in carnivore crania and dentition // Functional Ecology. Vol.19. P.337-343.

Millien V. 2006. Morphological evolution is accelerated among island mammals // PLoS Biology. 4(11): e321.

Nanova O.G. 2009. [Structure of Morphological Disparity in Three Species of Extant Carnivora (Mammalia: Carnivora)]. Avtoreferat Dissertatsii Kandidata Biologicheskikh Nauk [Abstract of PhD Dissertation in Zoology]. Moscow: M.V. Lomonosov Moscow State University. 20 p. [in Russian].

Nanova O.G. 2010. Age variability of morphometrics features in skulls of the mainland Arctic fox (Alopex lagopus lagopus) and the Commander Islands Arctic fox (A. l. beringensis, A. l. semenovi) // Zoologicheskii Zhurnal. Vol.89. P.871-881 [in Russian with English summary].

Olson E.C. \& Miller R.L. 1958. Morphological Integration. Chicago: University of Chicago Press. 376 p.

Pavlinov I.Ya. \& Nanova O.G. 2008. Geometric morphometry of the upper toothrow in the Eurasian Arctic fox (Alopex lagopus, Canidae) // Zoologicheskii Zhurnal. Vol.87. P.344-347 [in Russian with English summary].
Rohlf F.J. 1996. TPSdig. Version 1.11. New York: State University at Stony Brook.

Rohlf F.J. 2015. The tps series of software // Hystrix. Vol.26. P.9-12.

Rohlf F.J. \& Corti M. 2000. The use of two-block partial least-squares to study covariation in shape // Systematic Biology. Vol.49. P.740-753.

Smirin V.M., Goltsman M.E., Kruchenkova E.P., Ovsyannikov N.G. \& Safronov O.V. 1979. [Behaviour of Arctic foxes on the fur-seals rookery] // V.E. Sokolov (ed.). [Ecological Foundations of Conservation and Management of Carnivores Mammals]. Moscow: Nauka. P.164165 [in Russian].

Stock D.W. 2001. The genetic basis of modularity in the development and evolution of the vertebrate dentition // Philosophical Transactions of the Royal Society London. Vol.356. P.1633-1653.

Tsalkin V.I. 1944. [Cranium geographic variation of Eurasian Arctic foxes] // Zoologicheskii Zhurnal. Vol.23. P.156-169 [in Russian].

Wagner G.P. 1996. Homologues, natural kinds and the evolution of modularity // American Zoologist. Vol.6. P.36-43.

Zagrebelnyi S.V. 2000a. Feeding ecology of Commander Islands Arctic fox subspecies: from Bering Island (Alopex lagopus beringensis Merriam 1902) and Mednyi Island (A. l. semenovi Ognev 1931; Carnivora, Canidae) // Zoologicheskii Zhurnal. Vol.79. P.595-697 [in Russian with English summary].

Zagrebelnyi S.V. 2000b. [Commander Islands Arctic Fox Subspecies (Alopex lagopus beringensis Merriam, 1902 and Alopex lagopus semenovi Ognev, 1931): Features of Island Populations]. Avtoreferat Dissertatsii Kandidata Biologicheskikh Nauk [Abstract of PhD Dissertation in Zoology]. Moscow: M.V. Lomonosov Moscow State University. 20 p. [in Russian].

Zagrebelnyi S.V. \& Puzachenko A.Yu. 2006. Craniological variability of Arctic foxes of Bering Island Alopex lagopus beringensis, Mednyi Island A. l. semenovi, and mainland A. l. lagopus subspecies (Carnivora, Canidae) // Zoologicheskii Zhurnal. Vol.85. P.1007-1023 [in Russian with English summary]. 